\title{
Warming increases the top-down effects and metabolism of a subtidal herbivore
}

Ecological theory and experiments indicate that warming can increase the relative strength of top-down effects via alterations to metabolic rates in several different systems, thereby resulting in decreased plant biomass at higher temperatures. However, the general influence of increased environmental temperature on top-down effects is not well understood in systems where organisms experience relatively large variation in temperature. Rapid ocean temperature changes are pervasive throughout the Galápagos Islands due to upwelling and downwelling of internal waves, ENSO events and seasonality. We measured the effect of large, but not uncommon, water temperature variation on the metabolism and grazing rate of a common subtidal herbivore and on photosynthesis of their algal prey in the Galápagos Islands in July 2012. We found that green urchin consumption and metabolism were greater at the higher temperature treatment $\left(28^{\circ} \mathrm{C}\right)$, resulting in significantly less algal biomass. Our result that warming increased green urchin metabolic rates, even in a highly dynamic system, provides further support for a mechanistic link between environmental temperature and feeding rates. And further, our findings suggest individual response to temperature results in changes in top-down effects. And if this response is maintained over longer-time scales of days to weeks, this could translate to alterations of larger-scale ecological patterns, such as primary producer community composition and structure. 
1

2 Authors Lindsey A. Carr ${ }^{1,2 *}$, John F Bruno ${ }^{1}$

3

${ }^{1}$ Department of Biology, The University of North Carolina at Chapel Hill, Chapel Hill, NC 27599, USA.

$4 \quad{ }^{2}$ Galápagos Science Center (a UNC-USFQ Joint Partnership), San Cristobal Island, Galápagos Archipelago, Ecuador.

$5 \quad{ }^{*}$ Corresponding author:

6 Lindsey Carr

7 UNC Chapel Hill, Department of Biology, CB\#3280 Chapel Hill, NC 27599

8 lacarr@email.unc.edu

$9 \quad 9092607374$ 
The strength of herbivore-plant interactions determines the composition and distribution of primary producers in many marine communities (Lubchenco \& Gaines 1981, Hawkins \& Hartnoll 1983, Paine 1992, Duffy \& Hay 2000, Burkepile \& Hay 2006). Several studies have found that this interaction is influenced by sublethal changes in environmental temperature, via alterations to metabolic rates (O'Connor 2009, Kratina et al. 2012). For example, higher temperatures often cause increases in both primary production and consumption rates; however, due to differential temperature scaling of photosynthesis and respiration, consumption is predicted to increase relative to production at warmer temperatures (Allen et al. 2005, O'Connor 2009, O'Connor et al. 2009). In some circumstances, this could lead to lower standing plant biomass due to stronger top-down effects.

A growing body of literature demonstrates that in a warming world the relative strength of top-down effects increases (within a non-lethal or non-stressful thermal environment), in freshwater, marine and terrestrial systems (O'Connor 2009, Barton et al. 2009, O'Connor et al. 2009, Yvon-Durocher et al. 2010, Hoekman 2010, Kratina et al. 2012). To date, these experimental studies were conducted with relatively small but relevant changes in temperature (from ambient to $+6^{\circ} \mathrm{C}$ ). It is unclear to what degree temperature influences species interactions in systems where organisms experience higher temperature variation. For example, it is possible that high natural temperature variability selects for physiological tolerance of temperature change (i.e., plasticity). Hoekman (2010) used the wide range of temperatures $\left(10^{\circ} \mathrm{C}-35^{\circ} \mathrm{C}\right)$ experienced by the inquiline community in pitcher plants to determine how temperature influences the top-down effects of mosquito larvae on protozoa. He found mosquito larvae developed faster at the warmer temperatures, and consequently, had higher energy demands and 
fed on protozoa at a faster rate relative to slowly developing mosquito larvae. Yet there are few other studies that quantified the effect temperature has on top-down control in environments with highly dynamic temperature regimes.

We used the nearshore system in the Galápagos Islands to determine how temperature affects the metabolism and the strength of top-down effects of a common subtidal grazer, the green sea urchin (Lytechinus semituberculatus). Ocean temperature in the Galápagos is highly variable in space and time, ranging from $11^{\circ} \mathrm{C}-31^{\circ} \mathrm{C}$ due to upwelling and downwelling of internal waves, El Niño-Southern Oscillation (ENSO) events and seasonality. Sea urchins are a key grazer on macroalgae in marine systems and can regulate the benthic algal community productivity and structure (Paine 1980, Witman 1985, Hereu et al. 2005, Brandt et al. 2012). They are the most significant invertebrate grazer guild in the Galápagos Islands (Irving \& Witman 2009, Brandt et al. 2012), and at high densities can convert macroalgal assemblages to urchin barrens or pavements of encrusting algae (Ruttenberg 2001, Edgar et al. 2009).

Therefore, if urchins exert strong top-down control in a system with large spatial and temporal variation in environmental temperature, warmer temperatures should strengthen the top-down effect of urchins on macroalgal assemblages and possibly result in increased urchin barrens. We manipulated temperature in outdoor mesocosms and measured the effects on urchin grazing rate and metabolism, as well as plant photosynthesis. Our findings suggest warming strengthens the top-down effects of urchins and results in lower algal standing biomass.

\section{Methods}

\section{Study System}

The Galápagos Islands are located $965 \mathrm{~km}$ off the coast of Ecuador and are centered at the confluence of several oceanographic currents leading to a high degree of variability in ocean 
temperature and phytoplankton biomass. The Equatorial Undercurrent runs from west to east across the Pacific Basin and drives major upwelling as it collides with the western islands, resulting in cold and nutrient-rich waters around these islands (Houvenaghel 1978, 1984). The cool Humbolt Current delivers nutrient-rich water to the southern edge of the archipelago (Kessler 2006). The northeast region of the archipelago is strongly influenced by the warm, nutrient-poor waters of the North Equatorial Countercurrent (NECC, or the Panama current) (Kessler 2006). Both of these currents contribute to the South Equatorial Current (SEC), a westward flowing current that strongly influences the central region of the archipelago (Houvenaghel 1984) (Fig. 1).

The dominant influence of the SEC changes seasonally, depending on the location of the Intertropical Convergence Zone (ITCZ) (Houvenaghel 1984). The ITCZ is north of the equator during the Garùa (fine mist) season (May to December), and the Humbolt Current is the major contributor to the SEC. During the wet season (December to May) the ITCZ shifts towards the south and the dominant influence to the SEC is the NECC. This results in fluctuating gradients of temperature and resource availability throughout the central archipelago.

The maximum average SST across the archipelago occurs in February and March, with the minimum usually occurring in August or September (Houvenaghel 1978, Schaeffer et al. 2008) (Fig. 2). Temperature data were collected from two sites on San Cristobal (the easternmost island in the archipelago). During 2011, there was a cold season low of $13^{\circ} \mathrm{C}$ in November 2011 and a high of $25^{\circ} \mathrm{C}$ in July 2011. In 2012, there was a warm season high of $30^{\circ} \mathrm{C}$ in February 2012 and a low of $20^{\circ} \mathrm{C}$ in May 2012 (Fig. 2 and Supplemental Data File \#1). This annual cycle is interrupted during ENSO events (Barber \& Chavez 1983, Chavez et al. 1999). 

deeper EUC thermocline, warmer waters and decreased upwelling. This results in low standing stock of primary producers in the euphotic zone (Pennington et al. 2006); and, ultimately marine consumer populations, such as seabirds, marine iguanas, and sea lions, decrease in abundance (Valle et al. 1987, Laurie \& Brown 1990). In contrast, the cold ENSO phase (La Niña) occurs as the easterly trade winds strengthen, sea surface temperatures decrease, and upwelling intensifies resulting in higher standing stock of primary producers (Izumo et al. 2002). During La Niña, ocean temperature in the western islands can be as low as $11^{\circ} \mathrm{C}$ (Wellington et al. 2001).

In addition to regional-scale spatiotemporal variability in temperature and resource availability, the upwelling and downwelling of internal waves result in extreme and rapid temperature changes over smaller spatial and temporal scales (Witman \& Smith 2003). For example, over a 53-week period on a rocky subtidal wall in the central archipelago at depths between 3-12m, 20 cold water events were recorded where temperature dropped by 3-9 ${ }^{\circ} \mathrm{C}$ over a $25 \mathrm{hr}$ period (Witman \& Smith 2003).

Study organisms

We tested the effect of temperature on the common subtidal herbivore Lytechinus semituberculatus (green sea urchin) and the green macroalga Ulva sp. Lytechinus, Tripneustes depressus (white sea urchin), and Eucidaris galapagensis (slate pencil urchin) are the three most common urchin species in the Galápagos Islands and together comprise 91\% of urchin biomass (Brandt \& Guarderas 2002, Brandt et al. 2012). In rocky subtidal habitats throughout the archipelago at depths between 1-5m, Lytechinus and Eucidaris are the two most common urchins, while Tripneustes is rare (Table 1). Further, Lytechinus is a strong interactor and capable of converting algal turfs (brown filamentous turf, order Ectocarpales: Giffordia sp., 
102

103

104

105

106

107

108

Ectocarpus sp.) to urchin barrens in relatively short time periods, while Eucidaris does not have any detectable effect on the abundance of algal turfs (Irving \& Witman 2009).

Ulva sp. was chosen as a food item for Lytechinus for several reasons: 1) Ulva sp. are one of the most abundant macroalgal species, along with turf, crustose coralline algae, and

Sargassum, in the Galápagos nearshore habitats (Vinueza et al. 2006, Vinueza 2009); 2)

ephemeral species, like Ulva, are highly palatable for herbivores (Carpenter 1986); and 3) sea urchin fronts in the Galápagos appear to consume all macroalgal species except for brown species (e.g., Padina) (L. Carr personal observation) and damselfish turfs (Irving \& Witman 2009).

Urchins and Ulva were haphazardly collected from the southern part of San Cristobal Island (89³6’41.85’W, $0^{\circ} 55^{\prime} 39.36$ ”S), and were immediately transported to the laboratory in buckets filled with seawater. All urchins were collected from a depth of $\sim 1.5 \mathrm{~m}$. Study organisms were maintained in culture tanks indoors at $23^{\circ} \mathrm{C}$ (ambient sea water temperature) for two days prior to beginning water temperature adjustments. Assays were conducted in a shaded, outdoor facility at the joint UNC/USFQ Galápagos Science Center (San Cristobal Island, Galápagos).

Herbivore feeding rate

We conducted feeding rate assays in July 2012 to test the effect of two different temperatures $\left(14^{\circ} \mathrm{C}\right.$ or $\left.28^{\circ} \mathrm{C}\right)$ on green urchin grazing rates on Ulva. Water temperature in the culture tanks was adjusted from ambient $\left(23^{\circ} \mathrm{C}\right)$ to either $14^{\circ} \mathrm{C}$ or $28^{\circ} \mathrm{C}$ over a four-day period. This is within the time period of shallow subtidal temperature changes of this magnitude in the Galápagos (Witman \& Smith 2003). 
Ulva and urchins were placed in 4-L plastic container mesocosms and received a fresh supply of temperature-conditioned seawater every 12 hours. Temperature treatments were maintained with either Visi-Therm submersible individual heaters (Marineland, Blacksburg, Virginia, USA) or ice baths. Feeding assays were replicated twice ( $n=5$ replicates for each trial). Herbivore presence and absence treatments were randomly assigned in water tables. Each mesocosm was equipped with an iButton Thermochron datalogger (Dallas semiconductor, Dallas, Texas, USA) and water temperature was recorded every 5 minutes. Eight mesocosms were equipped with a HOBO Pendant temperature/light sensor (HOBO, Bourne, Massachusetts, USA) and relative light intensity was measured every 5 minutes.

Starting conditions for each mesocosm were $2.50 \pm 0.004 \mathrm{~g}$ of wet mass Ulva tissue and either three urchins or no urchins (control to test for autogenic loss). The average test size for the urchins in the mesocosms was $3.55 \pm 0.08 \mathrm{~cm}$, which is representative of the green sea urchin populations in southern San Cristobal ( $n=120$ from two sites measured in May and June 2011: minimum $2.75 \mathrm{~cm}$, maximum $5.8 \mathrm{~cm}$. Mean $\pm 1 \mathrm{SE}$ of $3.79 \pm 0.61 \mathrm{~cm})$.

Assays were terminated and final algal biomass was measured after 48 hrs (when 50\% of algal tissue was consumed (Tomas et al. 2011)). Biomass consumption was estimated as ([ $H_{\mathrm{i}}$ $\left.\times C_{\mathrm{f}} / C_{\mathrm{i}}\right]-H_{\mathrm{f}}$ ), where $H_{\mathrm{i}}$ and $H_{\mathrm{f}}$ were the initial and final wet weights of algal tissue in the presence of herbivores, and $C_{\mathrm{i}}$ and $C_{\mathrm{f}}$ were initial and final wet weights of the controls. Relative light intensity levels did not vary between mesocosms and was $326.06 \pm 19.7$ lumens/ft ${ }^{2}$. These light levels are less than the average relative light levels at $1.5 \mathrm{~m}$ depth in the field (886.86 \pm 74.07 lumens $/ \mathrm{ft}^{2}$ ), but are within the range of light conditions experienced throughout the tidal cycle at the southern sites of San Cristobal Island during the month of June (Table 1). 
of nesting. The analysis tested for one fixed effect (temperature treatment), covariate (urchin test

148 size), and one random effect (temporal block). Consumption data were log transformed to meet

149 the assumption of homogeneity of variances. The random effect was not significant $(p=0.183)$.

150 Therefore, results were pooled and the random effect was dropped, for final analysis of treatment

151 effects. All statistical analyses were performed in R (v. 2.15.2).

152 Respiration and Photosynthesis

153 To estimate the temperature response of metabolic pathways (net photosynthesis and 154 respiration), we measured oxygen production and consumption rates for Ulva and green urchins 155 in $0.6 \mathrm{~L}$ containers under conditions identical to the feeding rate assays. Initial and final oxygen concentrations were measured for Ulva ( $5 \pm 0.08 \mathrm{~g}$ of leaf tissue) and paired blanks (seawater only) ( $n=20$ replicates) using a YSI-200 oxygen sensor (Yellow Springs Instruments, Yellow Springs, Ohio, USA). Samples of Ulva tissue ( $5 \pm 0.08$ g) were obtained by using three Ulva “rosettes” plucked from the substrate by the holdfast. Rosettes used were similar sizes and no cutting or tearing was necessary. After the initial measurement, aquaria were covered with plastic to minimize oxygen exchange with the air and left for 2 hrs. Net photosynthesis rates were estimated by subtracting measurements of dark oxygen consumption from light oxygen production. Siikavuopio et al. (2008). Urchins were held at $23^{\circ} \mathrm{C}$ prior to oxygen consumption trials. One randomly selected urchin was placed into an airtight, closed-system respirometry chamber (0.6L) and water temperature was gradually adjusted over a 10 hour period to $14^{\circ} \mathrm{C}$ and then back up to 168 $28^{\circ} \mathrm{C}$ over a 30 hour period. Within the chamber was a mounted YSI 200 dissolved oxygen 
169

probe to measure oxygen concentrations (mg/L) and a pump for water circulation to prevent the development of strong oxygen and temperature gradients. The chamber was placed into a water bath to maintain temperature treatments. An individual urchin was then placed into the chamber and oxygen concentrations were measured every five minutes for one hour at each temperature treatment $\left(14^{\circ} \mathrm{C}\right.$ and $\left.28^{\circ} \mathrm{C}\right)$. Trials were repeated for 11 urchins. The mean weight specific oxygen consumption rate $\left(Q, \mathrm{mg} \mathrm{O}_{2} \mathrm{~kg}^{-1} \mathrm{~h}^{-1}\right)$ was calculated with the equation of Karamushko and Christiansen (2002):

$Q=\left(C_{0}-C_{t}\right) V / W T$

$C_{0}$ and $C_{t}$ are the initial and final oxygen concentration $\left(\mathrm{mg} \mathrm{O}_{2} \mathrm{l}^{-1}\right)$, respectively. $V$ is the volume (l) of the chamber minus the test urchin volume (test urchin volume was estimated from their biomass). $W$ is the biomass of the urchin in $\mathrm{kg} . T$ is the measurement time in hours. Oxygen consumption and production test were analyzed with a $t$ test on change in $\mathrm{O}_{2}$. All statistical analyses were conducted using R (version 2.15.2).

\section{Results}

Herbivore feeding rate

Temperatures in the cold mesocosms were maintained at $14.01 \pm 0.08^{\circ} \mathrm{C}$ and $14.03 \pm$ $0.07^{\circ} \mathrm{C}$ for trials 1 and 2 , respectively. Warm mesocosms for trials 1 and 2 were $28.06 \pm 0.09^{\circ} \mathrm{C}$ and $28.00 \pm 0.04^{\circ} \mathrm{C}$, respectively. The range of temperatures maintained across both trials was $13.54-14.47^{\circ} \mathrm{C}$ for the cold treatment and $27.56-28.5^{\circ} \mathrm{C}$ for the warm treatment (Fig. 3).

Green urchin consumption was 46\% higher at the warmer temperature $(p<0.0001)$ (Fig. 4A). Urchin test size was not a significant covariate $(p=0.87)$. 


\section{Respiration and Photosynthesis}

Green urchin metabolism was significantly higher at $28^{\circ} \mathrm{C}$ than at $14^{\circ} \mathrm{C}(p<0.001$, Fig 4B). Ulva oxygen consumption was greater at $28^{\circ} \mathrm{C}$ (at $14^{\circ} \mathrm{C}, 2.55 \pm 0.11 \mathrm{~g} \mathrm{O}_{2} \bullet \mathrm{g} \mathrm{tissue}^{-1} \bullet \mathrm{hr}^{-1}$; at $28^{\circ} \mathrm{C}, 3.24 \pm 0.13 \mathrm{~g} \mathrm{O}_{2} \cdot g$ tissue $\left.^{-1} \bullet \mathrm{hr}^{-1} ; p=0.004\right)$. Oxygen production was also greater at $28^{\circ} \mathrm{C}$ (at $14^{\circ} \mathrm{C}, 3.88 \pm 0.09 \mathrm{~g} \mathrm{O}_{2} \bullet \mathrm{g} \mathrm{tissue}^{-1} \cdot \mathrm{hr}^{-1}$; at $\left.28^{\circ} \mathrm{C}, 4.74 \pm 0.15 \mathrm{~g} \mathrm{O}_{2} \bullet \mathrm{g}_{\text {tissue }}{ }^{-1} \bullet \mathrm{hr}^{-1} ; p=0.01\right)$. However, net photosynthesis rates did not vary with temperature $(p=0.45$, Fig $4 \mathrm{C})$.

\section{Discussion}

Consistent with the predictions based on metabolic theory and a growing body of literature, our results indicated that sublethal warming significantly increases the strength of top-down effects. Specifically, we found a $14^{\circ} \mathrm{C}$ increase in temperature resulted in a $46 \%$ increase in grazing rate and lower standing plant biomass. Similar results have been found in other marine systems (O’Connor 2009: with herbivores there was a nearly 100\% decrease in algal net growth at high temperatures compared to growth at low temperatures with or without herbivores) and grasslands (Barton et al. 2009: warming of $1^{\circ} \mathrm{C}$ increased the strength of top-down indirect effects on grasses and forbs by 30-40\%).

One limitation of our study was that the urchins and algae might have acclimated to the $\sim 5^{\circ} \mathrm{C}$ temperature change had we warmed the treatment tanks more slowly or maintained the experiment for longer. Thus, it is difficult to extrapolate to how slower or longer-term changes in temperature will affect urchin-algal interactions and, consequently, larger spatial scale changes in ecological patterns. However, the rate of temperature change during the acclimation period and experiment is similar to temporal patterns of temperature fluctuation experienced by urchins around San Cristobal and the Galápagos Archipelago in general (Palacios 2004, Vinueza 2009, Witman et al. 2010). In this dynamic system, urchins rarely spend more than several days to a 
215 few weeks at the same temperature, suggesting that our experimental treatments were

216 representative of the natural temperature regime.

217

218

219

220

221

222

223

224

225

226

227

228

229

230

231

232

233

234

235

236

237

While there was a significant temperature effect on consumer metabolism and feeding rates, there was not a significant temperature effect on algal photosynthesis rates following the 4-day acclimation period in this study. It is possible that this was because light, nutrients, carbon dioxide, or some other resource was limiting and thus warming could not stimulate photosynthesis. Further, the positive effect of increased temperature on algal photosynthetic rate can be reduced or reversed at sub-saturating light levels because warming can increase the light level needed to reach the compensation point (Davison 1991). Light conditions in the experiment were within the range of light levels in the nearshore habitats in the Galápagos (Table 1) and further, most populations of subtidal algae are subject to subsaturating light conditions (Davison 1991); therefore the experimental conditions likely reflect algal performance in the field. Our results are consistent with O’Connor (2009) which found no temperature effect for Sargassum with a $4^{\circ} \mathrm{C}$ temperature change.

Organisms throughout the nearshore habitats of the Galápagos Islands experience large and frequent temperature fluctuations (Witman \& Smith 2003, Palacios 2004, Vinueza et al. 2006, Schaeffer et al. 2008, Vinueza 2009, Witman et al. 2010, Vinueza 2010). Therefore, populations in this environment could be less metabolically sensitive to extreme temperature changes due to adaptation, resulting in metabolic responses that deviate from the predicted outcomes of metabolic theory. For example, in the rocky intertidal, adaptive regulation results in reduced snail metabolic rates at warmer temperatures (Marshall \& McQuaid 2011). However, our results provide evidence that in a dynamic system where organisms experience relatively large variation in environmental temperature, metabolism and consumption still scale with 
238 temperature, which is consistent with metabolic theory (Allen et al. 2005, O'Connor 2009,

239 O'Connor et al. 2009).

At the upper range of species’ thermal tolerances metabolism and consumption are

241 predicted to scale differently and metabolic demands should outpace increased grazing intensity

242 (Rall et al. 2010). Lemoine and Burkepile (2012) found Lytechinus variegatus consumption and

243 metabolism scaled differently at temperatures beyond $29^{\circ} \mathrm{C}$, a $9^{\circ} \mathrm{C}$ increase from the starting

244 temperature treatment $\left(20^{\circ} \mathrm{C}\right)$. Ultimately, urchin ingestion efficiency was decreased at the

245 higher temperature, resulting in possible reduced consumer fitness. Because shallow subtidal

246 temperatures around San Cristobal reach $30^{\circ} \mathrm{C}$, future work should focus on understanding

247 Lytechinus metabolism/consumption ratios at the highest temperatures in the Galápagos and the

248 implications for species interactions and the strength of top-down effects under these conditions.

Our finding that warming increased urchin metabolism, even in a thermally variable

system, provides further support for a mechanistic link between environmental temperature and

feeding rates. Additionally, our findings indicate warming increases grazing intensity, which

252

could in turn affect ecological patterns, such as primary producer community composition and

biomass. For example, if these grazing rates are maintained over longer time-scales (i.e., days to

weeks), warmer temperatures may increase the prevalence of urchin barrens in areas of the

Galápagos with high densities of sea urchins because of the increased relative strength of

top-down effects. This study focused on one algal species and thus we cannot extrapolate to how

257

258

259

260

temperature would affect other algal-urchin interactions. Furthermore, macroalgal primary

production is highly seasonal in the Galapagos nearshore habitats (Vinueza et al. 2006, Vinueza 2009) and it is unclear what effect this could have on urchin-plant interaction strength. We also recognize that other factors influence urchin-plant interactions and primary production. Future 
work should focus on elucidating the stability of this interaction under larger temporal and spatial scales, and various environmental conditions (i.e., different seasons, ENSO cycles, varying light intensities, etc.) and with different algal species.

The absence of macroalgae in intertidal and shallow subtidal habitats during warm periods (e.g., El Niño) in the Galápagos Islands is generally attributed to the decreased strength of bottom-up forcing (i.e., upwelling) and subsequent lack of nutrients (Vinueza et al. 2006). However, temperature stress (i.e., desiccation) does play a minor role in regulating intertidal algal biomass in the Galápagos (Vinueza 2009). Therefore, future work should focus on understanding the constraints of physical stress on macroalgal growth in the Galápagos Islands, as stress is known to alter the relative importance of bottom-up and top-down effects (Thompson et al. 2004).

Low macroalgal biomass in warm seasons and years could also be due in part to increased grazing intensity due to higher temperature (e.g., O’Connor et al. 2009). Both mechanisms could be operating (i.e., changes in top-down and bottom-up control), although the relative strength of these mechanisms in influencing large-scale ecological patterns in upwelling systems is unknown. In freshwater pond systems, Kratina et al. (2012) found a negative interaction between warming and nutrient input on total phytoplankton biomass in freshwater systems, suggesting a shift toward stronger top-down and weaker bottom-up effects with warming regardless of nutrient availability. However, the mechanism behind this shift is not known. Therefore, future warming could result in stronger consumer control in systems where nutrients are plentiful (i.e., upwelling or well-mixed aquatic systems) that could lead to shortand /or long-term changes in community structure and function. 


\section{Acknowledgments}

285 We thank the Galápagos National Park, S. Walsh, C. Mena, P. Page, L. Vaca, and the Galápagos

286 Science Center for providing field and logistical assistance. I. Vu provided valuable field

287 assistance. We thank J. Witman whose input improved the experimental design. 
292

\section{REFERENCES}

Allen AP, Gilloly JF, Brown JH (2005) Linking the global carbon cycle to individual metabolism. Functional Ecology 19:202-213

Barber RT, Chavez FP (1983) Biological consequences of El Niño. Science 222:1203-1210

Barton BT, Beckerman AP, Schmitz OJ (2009) Climate warming strengthens interactions in an old-field food web. Ecology 90:2346-2351

Brandt M, Guarderas P (2002) Erizos de mar (E Danulat and GJ Edgar, Eds.). Servicio Parque Nacional Galápagos, Santa Cruz, Galápagos

Brandt M, Witman JD, Chiriboga AI (2012) Influence of a dominant consumer species reverses at increased diversity. Ecology 93:868-878

Burkepile DE, Hay ME (2006) Herbivore vs. nutrient control of marine primary producers: Context-dependent effects. Ecology 87:3128-3139

Carpenter RC (1986) Partitioning herbivory and its effects on coral reef algal communities. Ecological Monographs 56:345-364

Chavez FP, Strutton PG, Friederich GE, Feely RA, Feldman GC, Foley DF, McPhaden MJ (1999) Biological and chemical response of the Equatorial Pacific ocean to the 1997-1998 El Niño. Science 286:2126-2131

Davison IR (1991) Environmental effects on algal photosynthesis: temperature. Journal of Phycology 27:2-8

Duffy JE, Hay ME (2000) Strong impacts of grazing amphipods on the organization of a benthic community. Ecological Monographs 70:237-263

Edgar GJ, Banks SA, Brandt M, Bustamante RH, Chiriboga AI, Earle SA, Garske LE, Glynn PW, Grove JS, Henderson S, Hickman CP, Miller KA, Rivera F, Wellington GM (2009) El Niño, grazers and fisheries interact to greatly elevate extinction risk for Galapagos marine species. Global Change Biology 16:1-15

Hawkins SJ, Hartnoll RG (1983) Grazing of intertidal algae by marine invertebrates. Oceanography and Marine Biology: An Annual Review:195-282

Hereu B, Zabala M, Linares C, Sala E (2005) The effects of predator abundance and habitat structural complexity on survival of juvenile sea urchins. Mar Biol 146:293-299

Hoekman D (2010) Turning up the heat: Temperature influences the relative importance of top-down and bottom-up effects. Ecology 91:2819-2825

Houvenaghel GT (1978) Oceanographic conditions in the Galápagos Archipelago and their relationship with life on the islands. In: Boje R, Tomczak M (eds) Upwelling Ecosystems. 
Houvenaghel GT (1984) Oceanographic setting of the Galápagos Islands. In: R P (ed) Key Environments, Galápagos. Pergamon Press, Oxford, p 43-54

Irving AD, Witman JD (2009) Positive effects of damselfish override negative effects of urchins to prevent an algal habitat switch. Journal of Ecology 97:337-347

Izumo T, Picaut J, Blanke B (2002) Tropical pathways, equatorial undercurrent variability and the 1998 La Niña. Geophys Res Lett 29:2080-2083

Karamushko LI, Christiansen JS (2002) Aerobic scaling and resting metabolism in oviferous and post-spawning Barents Sea capelin Mallotus villosus (Muller, 1776). Journal of Experimental Marine Biology and Ecology 269:1-8

Kessler WS (2006) The circulation of the eastern tropical Pacific: A review. Progress in Oceanography 69:181-217

Kratina P, Greig HS, Thompson PL, Carvalho-Pereira TS, Shurin JB (2012) Warming modifies trophic cascades and eutrophication in experimental freshwater communities. Ecology 93:1421-1430

Laurie WA, Brown D (1990) Population biology of marine iguanas (Amblyrhynchus cristatus). II. Changes in annual survival rates and the effects of size, sex, age and fecundity in a population crash. Journal of Animal Ecology 59:529-544

Lubchenco J, Gaines SD (1981) A unified approach to marine plant-herbivore interactions. I. Populations and communities. Annual Review of Ecology and Systematics 12:405-437

Marshall DJ, McQuaid CD (2011) Warming reduces metabolic rate in marine snails: adaptation to fluctuating high temperatures challenges the metabolic theory of ecology. Proceedings of the Royal Society B: Biological Sciences 278:281-288

O'Connor MI (2009) Warming strengthens an herbivore-plant interaction. Ecology 90:388-398

O'Connor MI, Piehler MF, Leech DM, Anton A, Bruno JF (2009) Warming and resource availability shift food web structure and metabolism (M Loreau, Ed.). PLoS Biol 7:e1000178

Paine RT (1980) Food webs: Linkage, interaction strength and community infrastructure. Journal of Animal Ecology 49:666-685

Paine RT (1992) Food-web analysis through field measurement of per capita interaction strength. Nature 355:73-75

Palacios DM (2004) Seasonal patterns of sea-surface temperature and ocean color around the Galápagos: regional and local influences. Deep Sea Research Part II: Topical Studies in Oceanography 51:43-57 
Pennington JT, Mahoney KL, Kuwahara VS, Kolber DD, Calienes R, Chavez FP (2006) Primary production in the eastern tropical Pacific: A review. Progress in Oceanography 69:285-317

Rall BC, Vucic-Pestic O, Ehnes RB, Emmerson M, Brose U (2010) Temperature, predator-prey interaction strength and population stability. Global Change Biology 16:2145-2157

Ruttenberg BI (2001) Effects of artisanal fishing on marine communities in the Galápagos Islands. Conservation Biology 15:1691-1699

Siiavuopio I, Mortensen A, Christiansen JS (2008) Effects of body weight and temperature on feed intake, gonad growth and oxygen consumption in green sea urchin, Stronglyocentrotus droebachiensis. Aquaculture 281:77-82

Schaeffer BA, Morrison JM, Kamykowski D, Feldman GC, Xie L, Liu Y, Sweet W, McCulloch A, Banks S (2008) Phytoplankton biomass distribution and identification of productive habitats within the Galapagos Marine Reserve by MODIS, a surface acquisition system, and in-situ measurements. Remote Sensing of Environment 112:3044-3054

Tomas F, Abbott JM, Steinberg C, Balk M, Williams SL, Stachowicz JJ (2011) Plant genotype and nitrogen loading influence seagrass productivity, biochemistry, and plant-herbivore interactions. Ecology 92:1807-1817

Valle CA, Cruz F, Cruz JB, Merlen G, Coulter MC (1987) The impact of the 1982-1983 El Niño-Southern Oscillation on seabirds in the Galápagos Islands, Ecuador. Journal of Geophysical Research 92:437-444

Vinueza LR (2009) The role of herbivores and productivity on community structure of rocky shores of the Galápagos Islands, Ecuador. Oregon State University

Vinueza LR (2010) The role of herbivores and productivity on community structure of rocky shores of the Galápagos Islands, Ecuador.

Vinueza LR, Branch GM, Branch ML, Bustamante RH (2006) Top-down herbivory and bottom-up El Niño effects on Galápagos rocky-shore communities. Ecological Monographs 76:111-131

Wellington GM, Strong AE, Merlen G (2001) Sea surface temperature variation in the Galapagos Archipelago: A comparison between AVHRR nighttime satellite data and in situ instrumentation (1982-1998). Bulletin of Marine Science 69:27-42

Witman JD (1985) Refuges, biological disturbance, and ocky subtidal community structure in New England. Ecological Monographs 55:421-445

Witman JD, Smith F (2003) Rapid community change at a tropical upwelling site in the Galápagos Marine Reserve. Biodiversity and Conservation 12:25-45

Witman JD, Brandt M, Smith F (2010) Coupling between subtidal prey and consumers along a mesoscale upwelling gradient in the Galápagos Islands. Ecological Monographs 80:153-177 
389

390

391

392

393

394

395

392

Yvon-Durocher G, Jones JI, Trimmer M, Woodward G, Montoya JM (2010) Warming alters the metabolic balance of ecosystems. Philosophical Transactions of the Royal Society B:

Biological Sciences 365:2117-2126 


\section{Figure 1}

Map of Galápagos Archipelago and the surrounding currents

Colored triangles relate to curves in Fig. 2. Map courtesy of A. Valdivia and modified from Schaeffer et al. 2008.

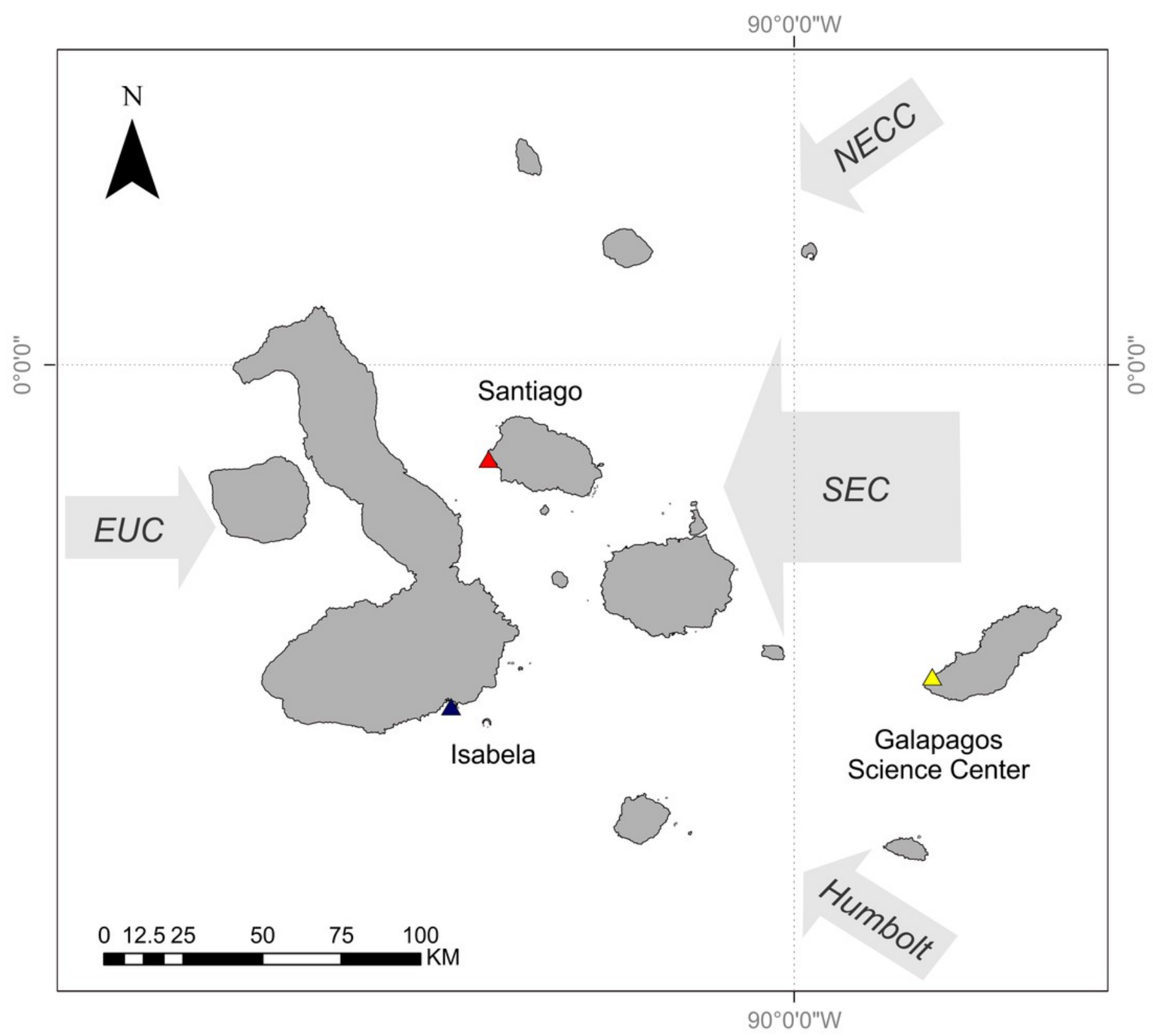




\section{Figure 2}

Daily water temperature (mean) measured in the shallow subtidal $(<5 \mathrm{~m})$ at Santiago, Isabela and San Cristobal.

The Galapagos Science Center is on San Cristobal. Water temperature measurements were recorded every 30 mins with a HOBO temp logger. The smoothing curve was done in Kaleidagraph (v. 4.1.). A Stineman function was applied to the data. The output of this function has a geometric weight that is applied to the data points and $\pm 10 \%$ of the data range to generate the smoothed curve.

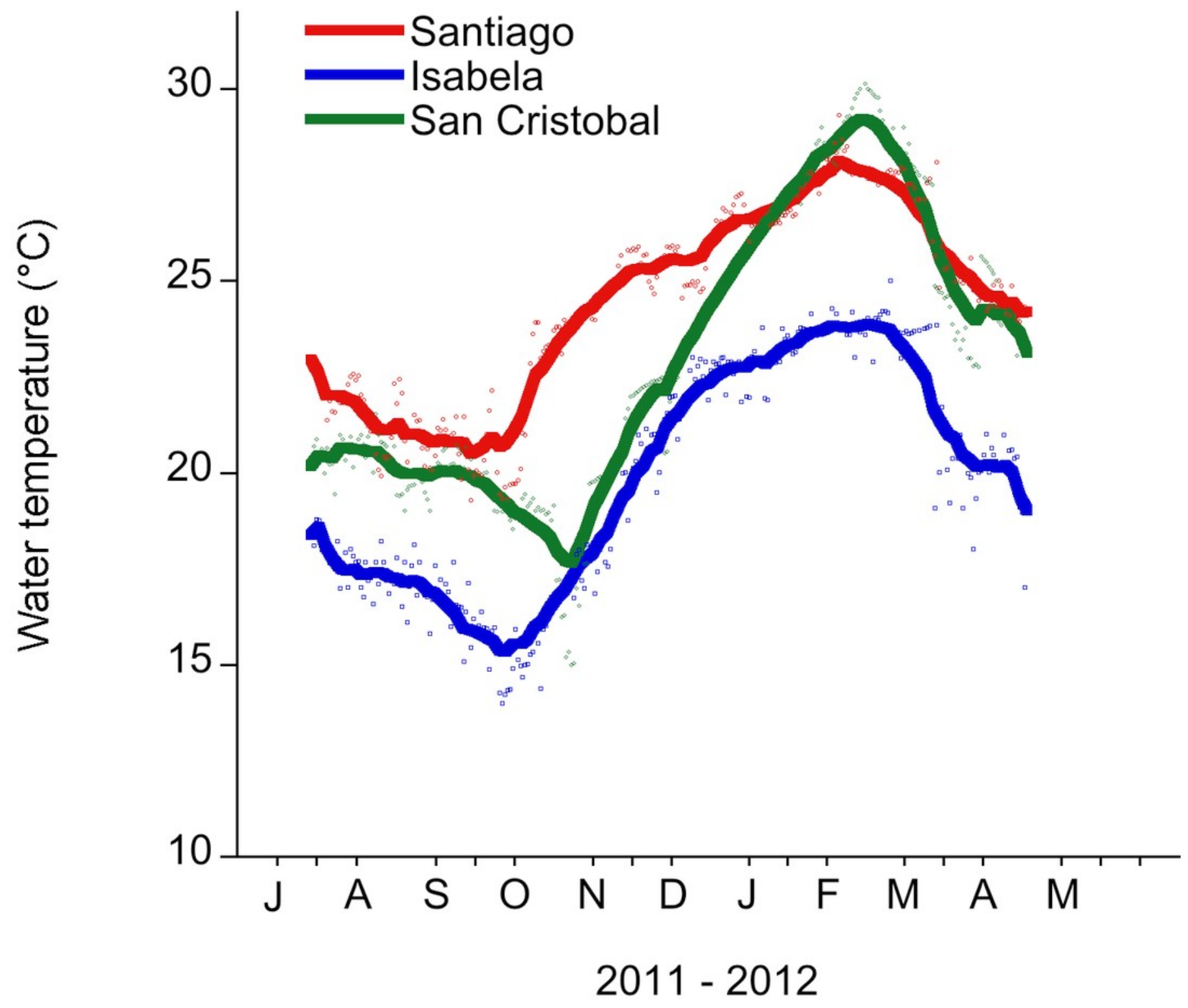




\section{Table $\mathbf{1}_{\text {(on next page) }}$}

Natural variation in algal cover, temperature and urchin density in shallow subtidal habitats in the Galápagos Islands.

Sites were surveyed in June 2010 and July 2012. Site codes: LL = La Loberia (San Cristobal, SC), LT $=$ Las Tijeretas (SC), PP = Punta Pitt (SC), CD = Cabo Douglas (Fernandina, FE), PE = Punta Espinosa (FE). Values represent means \pm SE ( $n=25$ quadrats for urchin density and algal cover). Any other urchin species (e.g., Tripneustes) were present at densities less than $0.3 \mathrm{~m}^{-2}$ in all quadrats. Temperature was estimated with both in situ temperature loggers and satellite data (AQUA Modis) for the 30-day period prior to sampling, SE $<0.07$ for all sampling points. Light intensity was measured using HOBO Light/Temperature Pendants before and during the experimental duration. 


\begin{tabular}{l|rrrr|rrr}
\hline Site & LL & LT & PP & CD & LL & LT & PE \\
\hline Ulva cover (\%) & $9.7 \pm 3.3$ & $58.4 \pm 3.5$ & $2.9 \pm 0.4$ & $36.3 \pm 5.1$ & $7.8 \pm 2.1$ & $28.9 \pm 2.7$ & $23.4 \pm 1.5$ \\
Eucidaris density $\left(\mathrm{m}^{-2}\right)$ & $4.8 \pm 1.3$ & $1.6 \pm 0.7$ & $1.6 \pm 0.2$ & $8.4 \pm 2.4$ & $6 \pm 1.9$ & $2.1 \pm 0.4$ & $3.2 \pm 1.3$ \\
Lytechinus density $\left(\mathrm{m}^{-2}\right)$ & $10.2 \pm 2.6$ & $11.8 \pm 1.8$ & $11.2 \pm 1.9$ & $1.2 \pm 0.7$ & $14.9 \pm 2$ & $13.2 \pm 1.6$ & $17.6 \pm 4.5$ \\
Temperature $\left({ }^{\circ} \mathrm{C}\right)$ & 24.8 & 23.7 & 20.8 & 11.4 & 25.3 & 23.2 & 17.8 \\
Light Intensity Range & & & & & & & \\
(lumens ft $\left.{ }^{-2}\right)$ & N/A & N/A & N/A & N/A & $0-3102$ & $0-2968$ & N/A
\end{tabular}




\section{Figure 3}

Mesocosm temperature values during both experiments

Temperature in each mesocosm ( $n=20$ per temperature) was recorded every 5 mins. with an iButton Thermochron datalogger (Dallas semiconductor, Dallas, Texas, USA). The box corresponds to the $25^{\text {th }}$ and $75^{\text {th }}$ percentiles and the dark line inside the box represents the median consumption value. Error bars are the minimum and maximum.

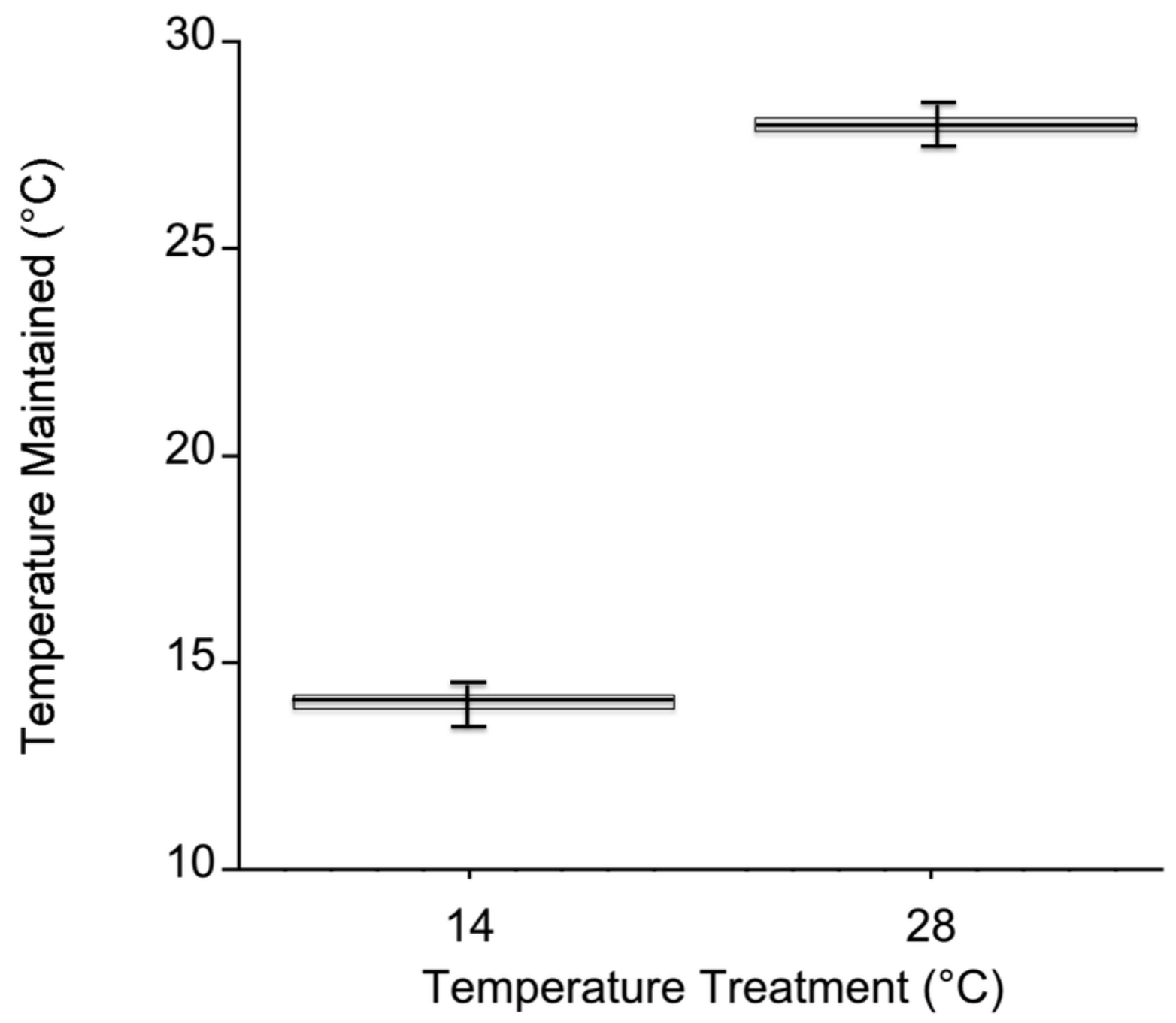




\section{Figure 4}

Temperature effects on urchin grazing rates, metabolism and algal photosynthesis

Temperature effects on A) urchin consumption of Ulva, B) urchin oxygen consumption, and C) on Ulva net photosynthesis. Values are means $\pm \mathrm{SE} ; \mathrm{n}=10$. 

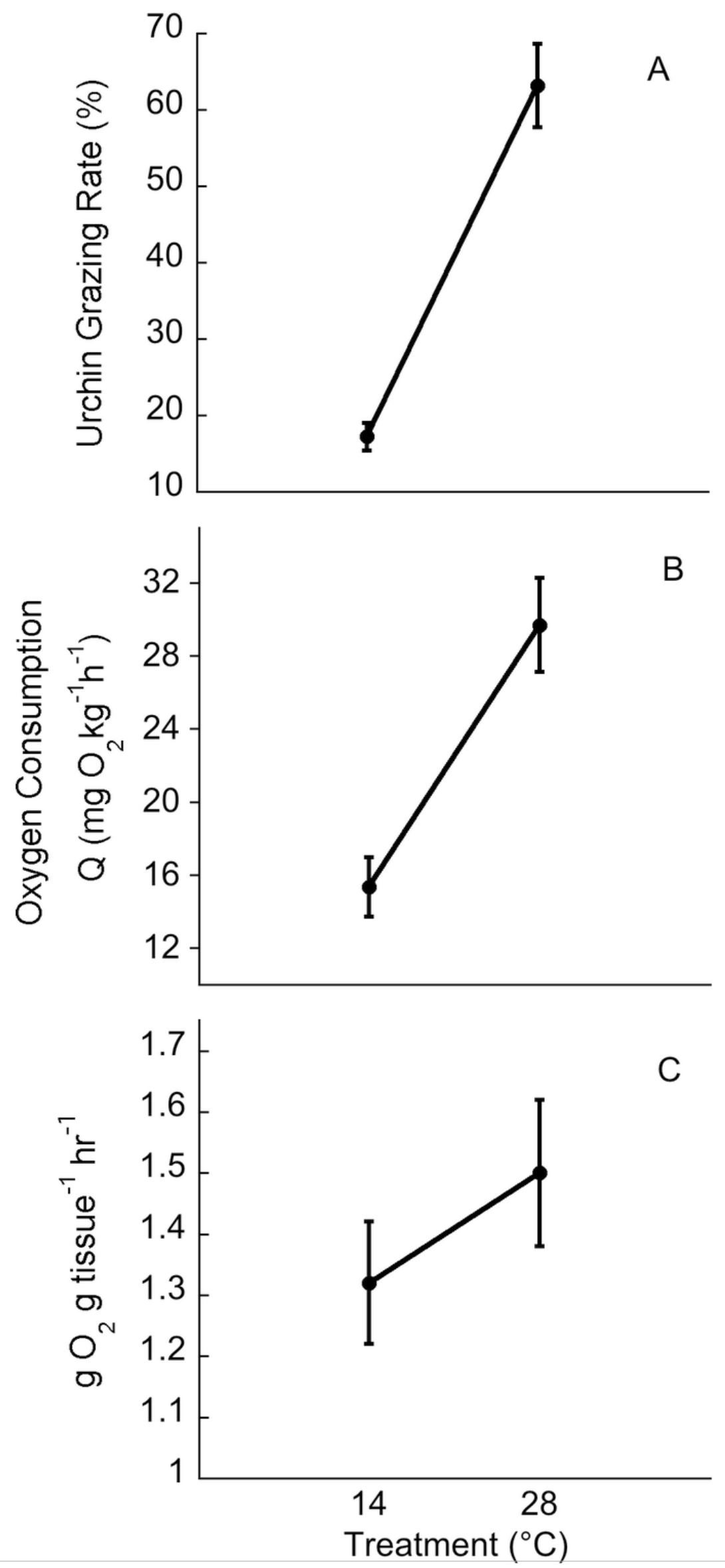

PeerJ reviewing PDF | (v2013:04:372:2:0:NEW 1 Jul 2013) 